\title{
PRECIPITATION AND FATAL MOTOR VEHICLE CRASHES Continental Analysis with High-Resolution Radar Data
}

\author{
Scott E. Stevens, Carl J. Schreck III, Shubhayu Saha, Jesse E. Bell, and Kenneth E. Kunkel
}

\author{
Precipitation, even at light intensity, contributes a significant risk of fatal motor vehicle \\ crashes across the United States, at nearly all times of day, and in all seasons.
}

A ccording to the Fourth National Climate Assessment (USGCRP 2018), "observed increases in the frequency and intensity of heavy precipitation events in most parts of the United States are projected to continue." Among the many public health concerns that these climatic changes portend is the impact on transportation safety (Pisano et al. 2003), as evidence suggests an increased frequency of fatal and nonfatal vehicle crashes associated with precipitation events. Motor vehicle traffic fatality is one of the leading causes of injury death across all age groups in the United States (National Center for

AfFiliations: SteVens, SChreCK, ANd KUnKel-Cooperative Institute for Climate and Satellites-North Carolina, North Carolina State University, Asheville, North Carolina; SAHANational Center for Environmental Health, Centers for Disease Control and Prevention, Atlanta, Georgia; BeLL-Department of Environmental, Agricultural and Occupational Health, College of Public Health, University of Nebraska Medical Center, Omaha, Nebraska

CORRESPONDING AUTHOR: Scott E. Stevens, scott@cicsnc.org

The abstract for this article can be found in this issue, following the table of contents.

DOI:10.II75/BAMS-D-18-0001.I

In final form 12 February 2019

(C)2019 American Meteorological Society

For information regarding reuse of this content and general copyright

information, consult the AMS Copyright Policy.
Health Statistics 2017), so understanding the risk of injury attributable to precipitation events is important. Adverse weather has implications for postcrash care management as well, affecting the response time for emergency medical professionals responding to a crash (Flanigan et al. 2014).

While numerous studies have investigated the link between rainy conditions and motor vehicle accidents, most have relied on either police reports (Saha et al. 2016) or station-based observations at the hourly to daily time scales, which require the assumption of a degree of homogeneity across time and space (Black et al. 2017; Andrey 2010; Andrey and Yagar 1993). A study area (e.g., a city or state) will be assumed to be uniformly wet or dry for a period that typically spans several hours. Precipitation varies on notoriously small temporal and spatial scales (Stow and Dirks 1998; Hrachowitz and Weiler 2011), so error can be introduced by using station observations even a few kilometers away that do not reflect conditions at the actual crash site (Fig. 1). For example, regarding an entire city as having experienced a rain event, when the reality is that $20 \%-30 \%$ of the area remained dry, can lead to overestimation in the risk of rainfall by attributing all of the crashes in the area to rain that may not have actually fallen everywhere. Jaroszweski and McNamara (2014) used radar estimates of precipitation to determine if an area is wet or dry. They deemed a city to have experienced a rain event if radar 
indicated that rain had fallen on more than $70 \%$ of the area for all of a 3-h period. Such an approach is necessary if one is to employ a matched-pair analysis, but runs the risk of attributing crashes in as much as $30 \%$ of the city to rain that never fell.

The availability of high-resolution radar data gives us the unique ability to determine prevailing meteorological conditions at the time and location of a fatal crash. Sun et al. (2011) used Next Generation Weather Radar (NEXRAD) data to study the effect of rainfall at high-resolution on several stretches of roadway in Louisiana and found a strong relationship between persistent rain and the risk of numerous types of crash. Other studies have used radar-derived estimates of precipitation to examine the risk of traffic crashes over the course of a day (Tamerius et al. 2016) and found a clear diurnal signal that suggests a higher weather-related risk during periods of heavier traffic.

Virtually all previous work agrees on an increase in the relative risk of a crash during precipitation, but the magnitude of the increase ranges widely, from as low as 1.10 (a 10\% increase in the likelihood of a crash) to as high as 1.76 (Black and Villarini 2019). In this analysis, we combine two nationally representative datasets to obtain information on 1) time and precise location of every reported fatal crash in the United
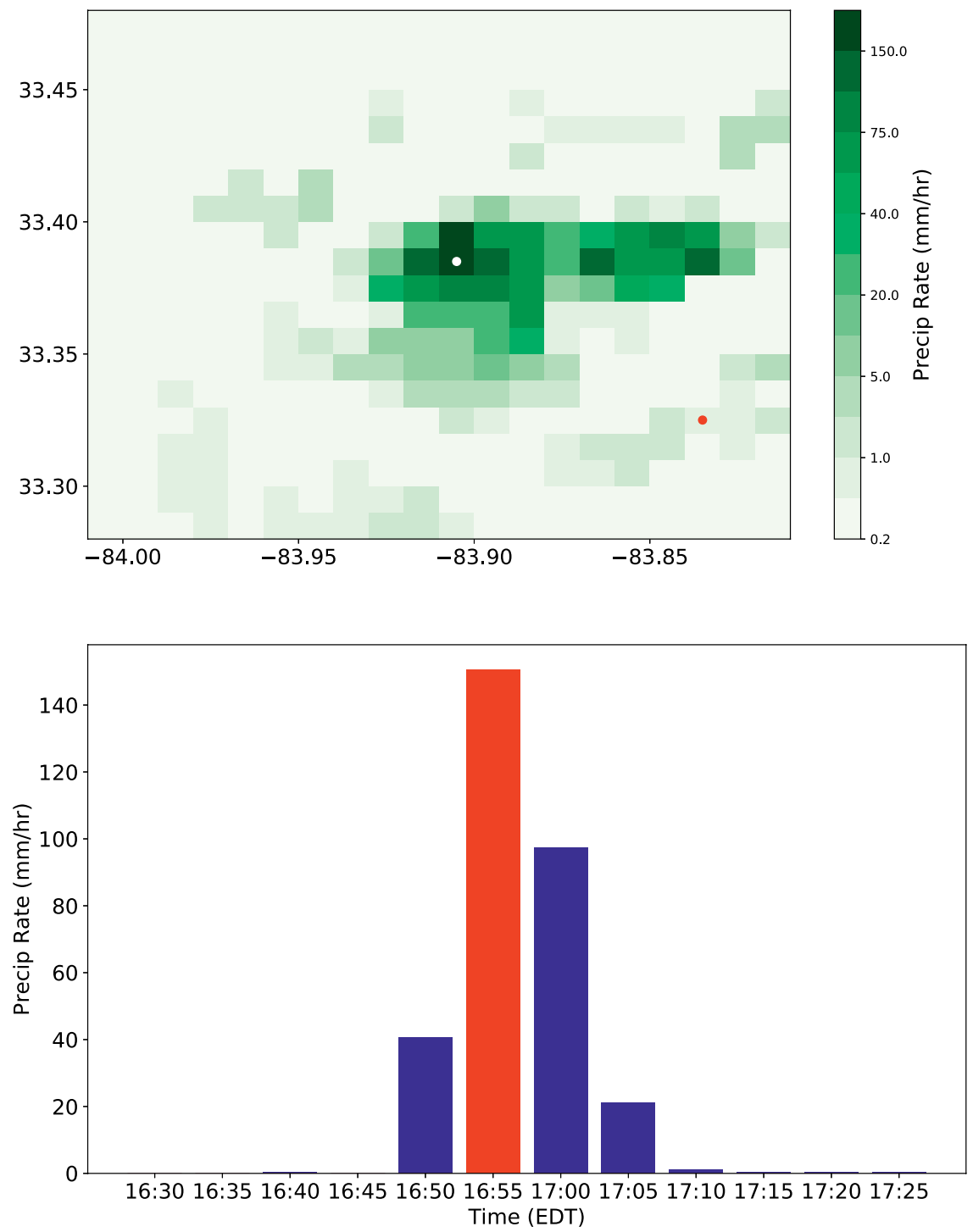

FIG. I. (top) NEXRAD-indicated precipitation rate at the time of a fatal crash (shown by the white dot) in Georgia. The nearest hourly weather station is located several kilometers to the southeast (red dot) and reported no precipitation for the entire day of the crash. (bottom) NEXRAD-indicated precipitation rate during each $5-\mathrm{min}$ period surrounding the same fatal crash. Accident took place at 1655 EDT.
States and 2) estimates of actual precipitation conditions at the time and location of the fatal crash for the continental United States. Previous studies using high-precision precipitation data for fatal crashes have focused on regional or local scales (Jaroszweski and McNamara 2014; Perrels et al. 2015). The National Oceanic and Atmospheric Administration's (NOAA) NEXRAD reanalysis (Nelson et al. 2017) provides a unique opportunity to study these relationships for the entire continental United States over a 6-yr period. Given the availability of data at such a fine spatial and temporal resolution $\left(0.01^{\circ} \times 0.01^{\circ}, 5 \mathrm{~min}\right)$, we seek to investigate the effect of precipitation that is actively falling (or not) at the time of a crash, rather than the after-effects such as a wet or icy road. While pooling statistics still allows for analyses grouped by time and space, the high resolution of this dataset enables us to consider the weather conditions specifically matched to each individual crash at very nearly its exact time and location. 
In this article, we examine 1) the association of precipitation with fatal traffic crashes, 2) the impact of precipitation intensity, and 3) how this association changes across seasons, regions, and time of day.

METHODS. Database of fatal accidents. We used the Fatality Analysis Reporting System (FARS) dataset for 2006-11 from the National Highway Traffic Safety Administration (NHTSA) to retrieve information surrounding 193,840 fatal crashes that occurred throughout the continental United States (NHTSA 2018). FARS contains the census of all traffic crashes on public roads in the United States that resulted in at least one death within 30 days of the crash. For each crash, the database contains information on the time and location of the crash (latitude and longitude), along with relevant personal and behavioral information pertaining to known risk factors for traffic crashes (e.g., use of alcohol and other drugs). The law enforcement official investigating the crash scene records all of this information on the crash report. To eliminate as much of the effect of alcohol and other drugs as possible, this study excludes any fatal crash in which the involvement of either is noted in the police report. This leaves 125,012 fatal crashes of the original 193,840 . Since the official that reports the fatal crash is often not an eyewitness to the incident itself, estimation errors can occur in the reporting. For example, we observe a notable increase in the frequency of crashes at the top and bottom of the hour, likely the result of times of crashes being estimated. This can introduce challenges when matching crash times to precipitation estimates on such a fine scale. However, there is little reason to suspect the introduction of any prescribed bias. Circumstances surrounding the crash are likewise reported by the investigating official, including weather and road conditions. While it has been shown that these reports generally agree with station data at short distances (Chung et al. 2018), many locations in the United States are more distant from reporting stations, and precipitation is known to vary dramatically even over short to moderate distances. In Canada, these reports have been shown to underestimate the frequency of weather as a contributing factor in crashes when compared to insurance claims (Mills et al. 2011).

NEXRAD reanalysis. Based on algorithms developed at the National Severe Storms Laboratory (NSSL),
NOAA's NEXRAD reanalysis provides a $0.01^{\circ} \times 0.01^{\circ}$ latitude-longitude estimate of precipitation rate on a 5-min time scale, derived primarily from NEXRAD reflectivities, coupled with Rapid Update Cycle model analysis to determine precipitation type (Zhang et al. 2011). Estimates at the hourly scale and longer are gauge-adjusted using hourly gauges across the United States, but subhourly precipitation rates are not, due to the lack of finescale subhourly gauges available. These algorithms have been retroactively applied to all archived NEXRAD data covering the years 2000-11, in a joint project between NSSL and NOAA's National Centers for Environmental Information (NCEI). The result is a high-resolution, high-frequency gridded precipitation estimate that allows for the retrieval of precipitation rates for the continental United States (Nelson et al. 2017).

The sparsity of radar antennas in the western United States results in many points that are quite distant from any antenna (Maddox et al. 2002), which degrades resolution, can result in beam overshooting of precipitation, and provides less data with which to create a precipitation estimate. In addition, areas of complex terrain are subject to beam blockage in valleys (Krajewski et al. 2006). However, in areas of good radar coverage, the NEXRAD estimate has been found to perform well against rain gauge networks $(\mathrm{Wu}$ et al. 2012; Stenz et al. 2014), particularly in stratiform regimes (Chen et al. 2013). Furthermore, the effect of any imprecision in this estimate is small in this context, as we are primarily concerned with the presence or absence of precipitation, rather than the precise rate.

Determining risk of a fatal crash due to precipitation. The strength of the relationship between precipitation and crashes is tested using relative risk, which is defined as $p_{1} / p_{0}$, where $p_{1}$ represents the probability of a crash in the presence of precipitation, and $p_{0}$ represents the probability of a crash in its absence. Thus, using the contingency table shown in Table 1, relative risk can be calculated as

$$
\frac{\mathrm{A} /(\mathrm{A}+\mathrm{C})}{\mathrm{B} /(\mathrm{B}+\mathrm{D})} \text {. }
$$


To measure the increased risk, we compare the fraction of crashes that occur during precipitation to a weighted climatology based on the same time and season at each respective point. Every 5-min precipitation estimate at the NEXRAD pixel containing the crash site is classified as either dry or wet (A or B), over its entire period of record (2000-11). The climatological frequency of precipitation according to the NEXRAD reanalysis at that location, controlled for the time and season of the crash, provides a ratio which can be used to supply a robust $C$ and $D$ that is unique to the exact location, time, and season of each crash. The entire table can then be summed for any selection of crashes to obtain a single value of relative risk for a given hour, month, region, or any combination thereof. Wet periods are further subdivided into light $\left(<2.5 \mathrm{~mm} \mathrm{~h}^{-1}\right)$, moderate $\left(2.5-7.6 \mathrm{~mm} \mathrm{~h}^{-1}\right)$, and heavy $\left(>7.6 \mathrm{~mm} \mathrm{~h}^{-1}\right)$ precipitation, according to classifications used by the American Meteorological Society's Glossary of Meteorology (American Meteorological Society 2012). We implicitly assume that selecting for location, hour of day, and month controls for all other risk factors such that they vary randomly from one crash to another with no relationship to the presence of precipitation or to its climatological frequency, providing us with an approach similar to that of a matched-pair analysis. To quantify the uncertainty in this estimate, we perform a 1,000-iteration bootstrap, which provides us with a robust $95 \%$ confidence interval in our estimate of relative risk. This analysis is repeated for each of

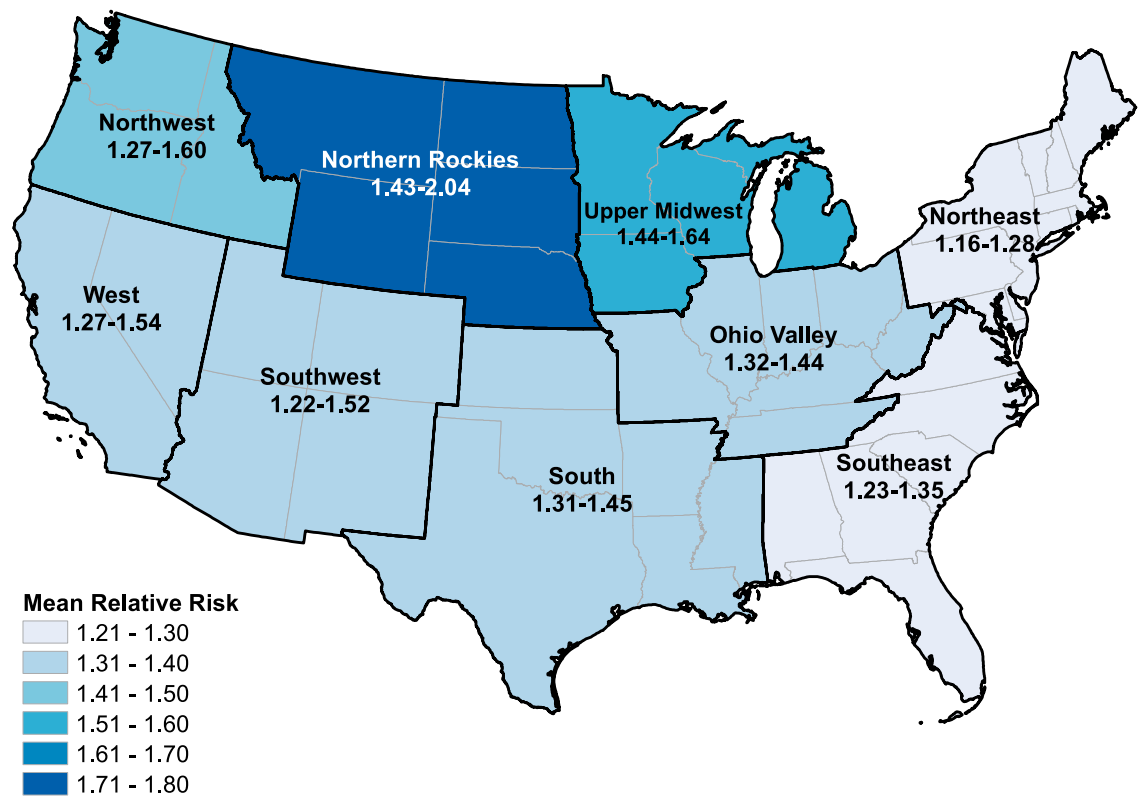

FIG. 2. Relative risk of a fatal crash due to precipitation by region. Range represents $95 \%$ confidence interval. the nine regions of the continental United States laid out in Karl et al. (1984).

RESULTS. Out of 125,012 fatal crashes studied where the effects of alcohol and other drugs were not noted, NEXRAD indicates falling precipitation in 9,636 cases (7.7\%), compared to a weighted climatology that indicates such conditions only $5.8 \%$ of the time. The overall relative risk of falling precipitation with regard to fatal crashes is 1.343 , representing a $34 \%$ increase in the likelihood of a fatal crash during precipitation. The 95\% confidence interval is 1.315-1.371. This falls within the range found by Black and Villarini (2019), who noted relative risk values ranging from 1.10 to 1.76 , although the bulk of these studies include all crashes, rather than only those with fatal outcomes. Regionally, the risk varies from a low of 1.22 in the Northeast to 1.74 in the Northern Rockies (Fig. 2).

Precipitation intensity. Due to decreased visibility and road traction, one may expect the effect of precipitation on fatal crashes to scale with intensity. As the rate of precipitation increases, driver visibility quickly degrades, and water may begin to pool on road surfaces, increasing the risk of hydroplaning. On the daily scale, Hambly et al. (2013) found a clear relationship between the magnitude of daily precipitation and the risk of a crash (with or without casualties), with the relative risk on heavy precipitation days $(>20 \mathrm{~mm})$ rising to 1.47 . Black and Villarini (2019) find a similar positive relationship between hourly precipitation totals and the relative risk of a crash. We find, on the instantaneous level, that risk increases more dramatically with heavier precipitation, nearly doubling from 1.27 during light precipitation to 2.46 during heavy precipitation (Fig. 3, blue bars). The differences in the relative risk for each precipitation category are statistically significantly different from one another, despite the rapidly decreasing sample sizes at heavier precipitation rates (Fig. 3, red bars).

Variation throughout the day. Day and night bring different hazards, with nighttime resulting in decreased 


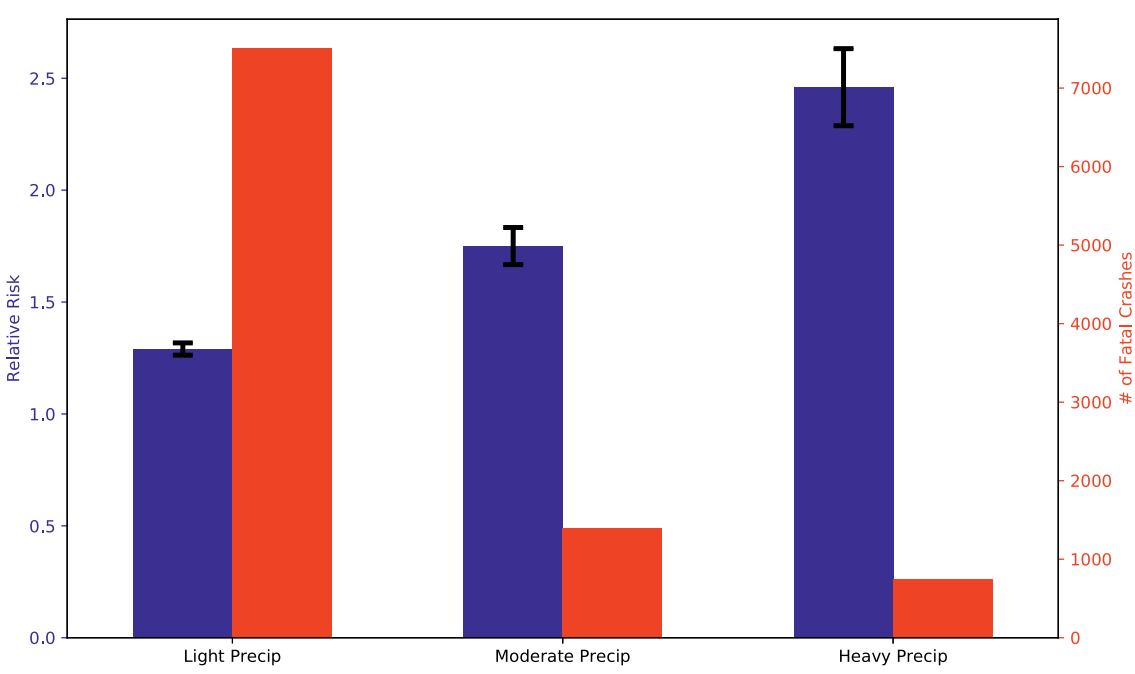

FIG. 3. Relative risk (blue, left axis) and number of fatal crashes (red, right axis) associated with light, moderate, and heavy precipitation. Error bars indicate $95 \%$ confidence interval.

visibility but also decreased traffic density. The relative risk of precipitation ranges from roughly 1.0 (no increased risk) during the overnight hours to a maximum of 1.6 during the morning rush hour (Fig. 4). While the total number of fatal accidents peaks in the evening hours, in agreement with Black and Mote (2015), we still find the risk associated with precipitation to peak during the morning. The difference between day and night is statistically significant, and can possibly be attributed to the lack of vehicles on the road during the night, reducing the number of collision opportunities.

Seasonal signal. As rain gives way to snow and ice throughout much of the United States, the risk of weather-related fatal crashes is expected to increase during the winter months (Qiu and Nixon 2008). We find this signal clearly evident, with the winter months showing a marked increase in the risk of precipitation (Fig. 5). This seasonal variability is likely the result of snowfall during the winter months, and this hypothesis is supported by the fatal crashes by hour of day. regional variation in the strength of the seasonal signal. Figure 6 shows the ratio of the relative risks in winter (DecemberFebruary) and summer (June-August). Most regions show a higher risk during the winter, with the largest differences found in the Northern Rockies and Upper Midwest, areas characterized by frequent snowfall during the winter. In areas with relatively little winter precipitation (e.g., Northwest, Southeast), the signal is predictably much weaker, or even inverted.
DISCUSSION. Using a high-resolution precipitation estimate that allows for near-instantaneous assessment of the weather conditions surrounding a fatal crash, we find a strong association between precipitation and fatal traffic crashes for the entire continental United States, and this holds true in all regions, although at varying degrees. The relative risk overall is approximately 1.34 , which falls in line with previous work, although much of the literature
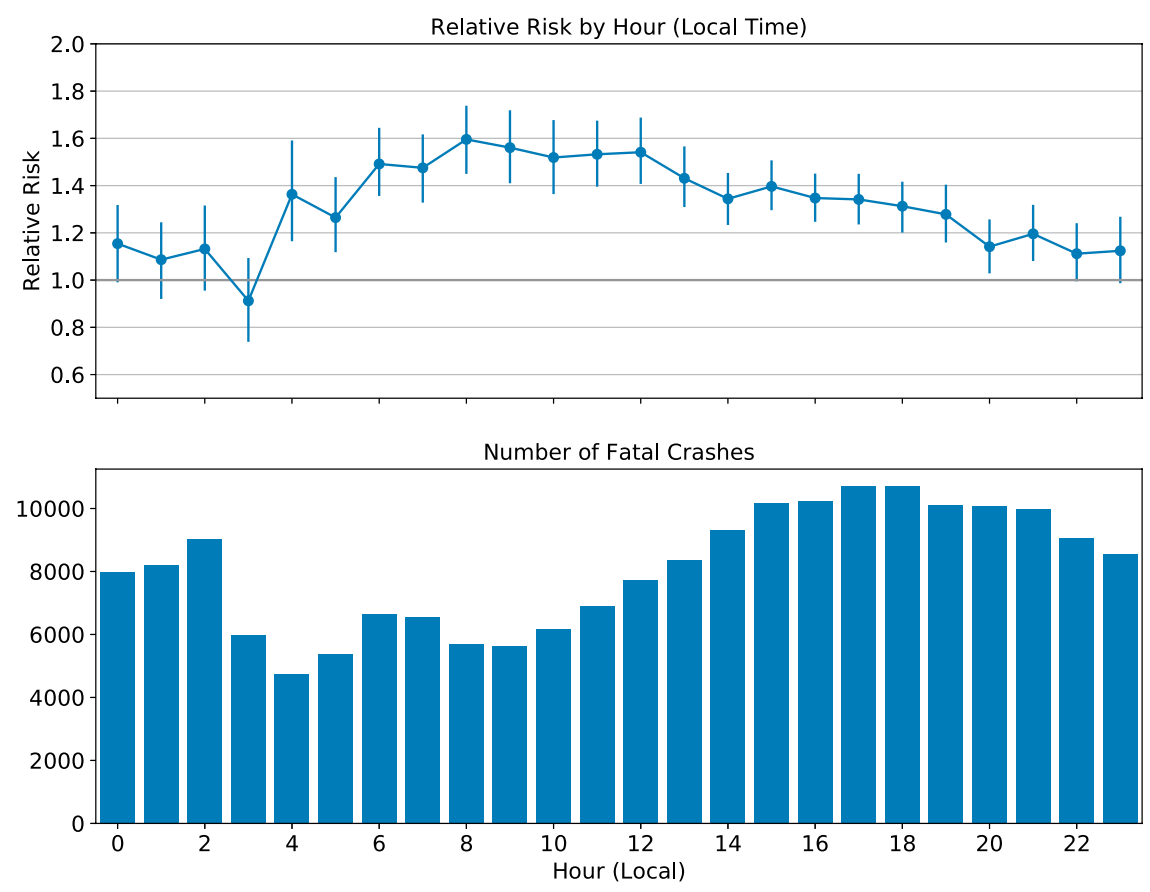

FIG. 4. (top) Relative risk for all precipitation and (bottom) number of total 
has investigated all reported crashes, rather than just fatalities. Studies that have focused on fatal crashes have typically found lower values of relative risk than this study (Black and Villarini 2019), although these studies have normally used coarser data in both time and space. It is notable that we come to this number by only investigating the precipitation conditions at nearly the exact time of a crash, with no regard to precipitation that may have fallen earlier, thus impacting the road conditions. This suggests that a great deal of the risk due to precipitation is applicable only while it is actively falling, rather than afterward. This agrees with Andrey and Yagar (1993), who found that the risk due to rainfall drops significantly immediately after a rain event. In addition, finding relative risk values in line with previous work that has employed precipitation data aggregated over time and space provides some validation for those methods and suggests that precision is not significantly lost by doing so, however our risk values start to diverge from the literature at heavier precipitation rates.

Not surprisingly, the risk of a fatal crash due to precipitation is lowest at light rates, although still greater than unity [relative risk $(\mathrm{RR})=1.29$, confidence interval $(\mathrm{CI})=(1.26,1.32)]$. As heavier rates degrade visibility and road conditions, the risk scales accordingly, with the risk of a fatal crash during heavy precipitation found to be more than double the background risk $[\mathrm{RR}=2.46, \mathrm{CI}=(2.29,2.63)]$. This finding is considerably higher than that found in previous work (Hambly et al. 2013), which highlights the value of being able to isolate the narrow time window during which a crash occurred, as exceptionally heavy precipitation rates are often washed out by aggregating to longer time scales. Diurnally, we find a notable difference between day and night, with the highest risk of a fatal crash due to precipitation occurring during the morning rush hour, when traffic is congested and provides more opportunity for a collision. This is expected based on previous studies that found a similar pattern (Tamerius et al. 2016), but we find the same even when looking exclusively at fatal crashes. The lack of a second spike in relative risk during the evening rush hour could possibly be attributed to the lower likelihood of low visibility conditions (Stevens 2019) or frozen precipitation in the evening hours.

The National Climate Assessment (USGCRP 2018) reported that average annual precipitation for the United States has increased since 1900, with variability based on the climate region (Peterson et al. 2013; USGCRP 2018). Based on the results of our study, areas with increasing precipitation would likely be more susceptible to fatal motor vehicle crashes because of increased exposure. The seasonal timing of the precipitation is also very important. The regional differences in the risk of precipitation during winter suggest that winter precipitation is particularly hazardous, so areas that experience increasing winter precipitation may be especially at risk of an increase in fatal crashes. The way precipitation is falling is also changing nationally. Heavier downpours are becoming more common nationally and are projected to continue to increase in the future (Kunkel et al. 2013). Combined with the strong correlation between heavier precipitation and fatal crashes, the implication is that ever-increasing exposure to heavy downpours may lead to an associated climb in fatal crashes, a conclusion supported by other work such as Hambly et al. (2013). The continued monitoring of these 


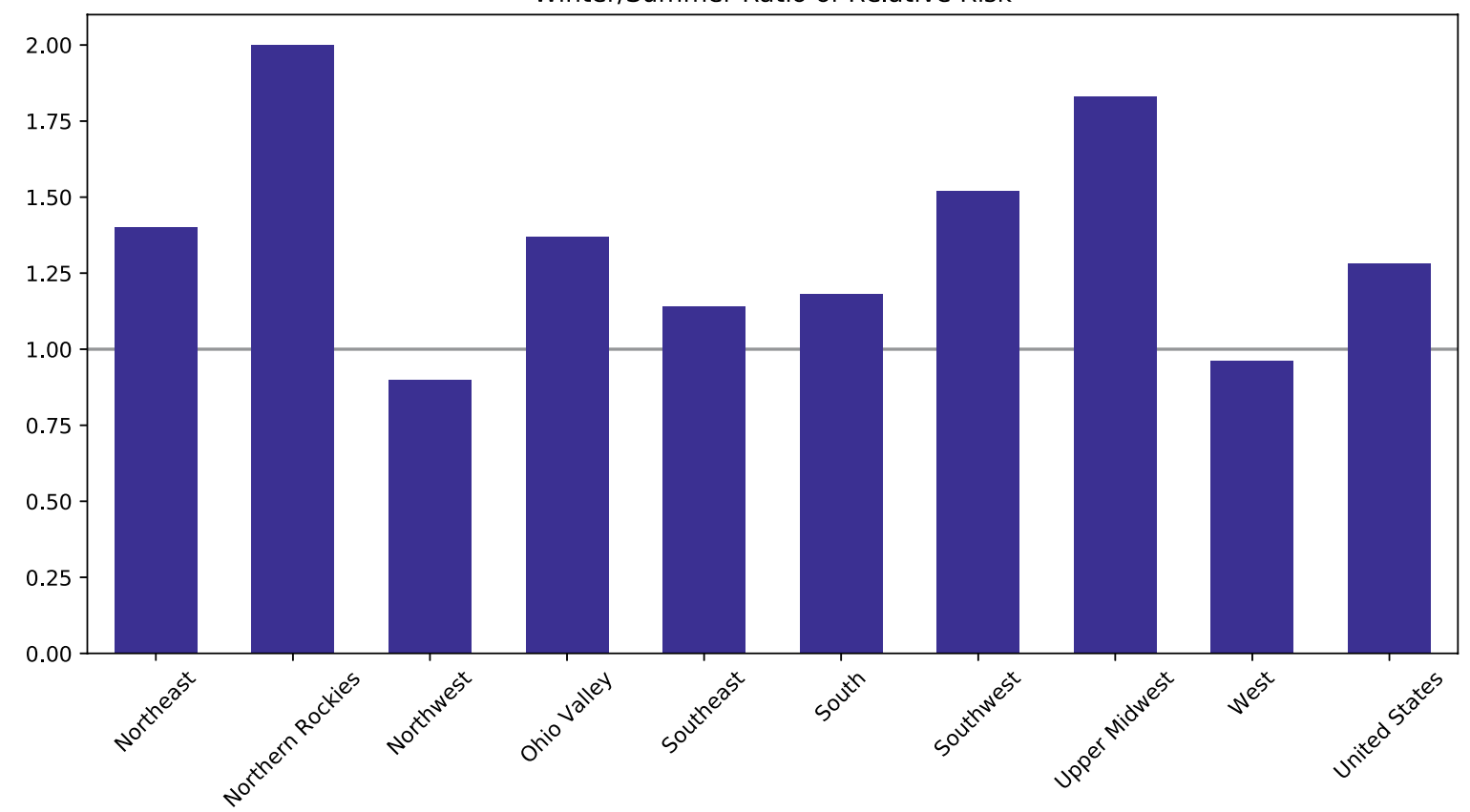

Fig. 6. Ratio of relative risk in winter (Dec-Feb) vs summer (Jun-Aug) by region.

relationships with high precision data is necessary to identify the changes that occur over time and build relationships that could help reduce risks.

Our results show that precipitation at all intensities contributes a significant risk to fatal traffic crashes. These results highlight the need for greater research in incorporating accurate and location-specific weather information in designing weather-responsive traffic management strategies (Pisano and Goodwin 2004). Deployment of environmental sensors as part of roadway weather information systems (Jin et al. 2014) is being considered across the Department of Transportation, which might have an impact on injury prevention. While awareness campaigns and laws have long been established regarding the dangers of alcohol-impaired driving (Eisenberg 2003), recent pushes have been made to expand into less-appreciated risk factors such as driving while drowsy or using a mobile device (Strayer et al. 2006; Nelson et al. 2009). Precipitation, particularly light precipitation, may be another of these underappreciated risks, with most drivers confident that their risk is not substantially increased during a precipitation event. A greater recognition of the added risk of precipitation with regard to traffic fatalities on the part of traffic engineers and public safety agencies could result in more timely advisories and more widespread awareness of the danger posed. Warnings of icy conditions on a specific curve in California were found to significantly reduce driving speed (Veneziano et al. 2014). Effective means of communicating the risk from hazardous weather that lead to adoption of protective measures by the public remain an active area of research (Barjenbruch et al. 2016). Possible strategies include early-warning systems that alert drivers to impending precipitation, or the expansion of variable speed limits that adapt to road conditions.

A logical extension of this work is the exploration of precipitation type. While precipitation type is a part of the NEXRAD reanalysis, it is currently an estimate based on model temperature data rather than radar returns and was not used in this study to make a determination of the type of precipitation falling at the time of a fatal crash. The proliferation of dual-polarization radar throughout the NEXRAD network will allow for better discrimination of precipitation types in the future (Chandrasekar et al. 2013; Grazioli et al. 2015), which will result in the ability to distinguish our results associated with rain versus those associated with snow and ice.

The risk of a fatal crash is measurably and significantly increased by falling precipitation, even at light rates, in all regions of the continental United States, even without considering after-effects such as wet roads that may linger after the precipitation has stopped. Investigating this relationship at high resolution confirms results found by previous work that utilized coarser data, and suggests that the impact of heavy precipitation may be greater than previously thought. 
ACKNOWLEDGMENTS. This work was supported by NOAA through the Cooperative Institute for Climate and Satellites-North Carolina under Cooperative Agreement NA14NES432003. The findings and conclusions in this report are those of the authors and do not necessarily represent the views of the Centers for Disease Control and Prevention.

\section{REFERENCES}

American Meteorological Society, 2012: "Rain." Glossary of Meteorology, accessed 26 April 2018, http:/glossary.ametsoc.org/wiki/Rain.

Andrey, J., 2010: Long-term trends in weather-related crash risks. J. Transp. Geogr., 18, 247-258, https:// doi.org/10.1016/j.jtrangeo.2009.05.002.

— related crash risk. Accid. Anal. Prev., 24, 465-472, https://doi.org/10.1016/0001-4575(93)90076-9.

Barjenbruch, K., and Coauthors, 2016: Drivers' awareness of and response to two significant winter storms impacting a metropolitan area in the Intermountain West: Implications for improving traffic flow in inclement weather. Wea. Climate Soc., 8, 475-491, https://doi.org/10.1175/WCAS-D-16 -0017.1 .

Black, A. W., and T. L. Mote, 2015: Characteristics of winter-precipitation-related transportation fatalities in the United States. Wea. Climate Soc., 7, 133-145, https://doi.org/10.1175/WCAS-D-14-00011.1.

_ , and G. Villarini, 2019: Effects of methodological decisions on rainfall-related crash relative risk estimates. Accid. Anal. Prev., https://doi.org/10.1016/j .aap.2018.01.023, in press.

-,- , and T. L. Mote, 2017: Effects of rainfall on vehicle crashes in six U.S. states. Wea. Climate Soc., 9, 53-70, https://doi.org/10.1175/WCAS-D-16 -0035.1 .

Chandrasekar, V., R. Keränen, S. Lim, and D. Moisseev, 2013: Recent advances in classification of observations from dual polarization weather radars. Atmos. Res., 119, 97-111, https://doi.org/10.1016/j .atmosres.2011.08.014.

Chen, S., and Coauthors, 2013: Evaluation and uncertainty estimation of NOAA/NSSL next-generation National Mosaic Quantitative Precipitation Estimation product $(\mathrm{Q} 2)$ over the continental United States. J. Hydrometeor., 14, 1308-1322, https://doi .org/10.1175/JHM-D-12-0150.1.

Chung, W., M. Abdel-Aty, and J. Lee, 2018: Spatial analysis of the effective coverage of land-based weather stations for traffic crashes. Appl. Geogr., 90, 17-27, https://doi.org/10.1016/j.apgeog.2017.11.010.
Eisenberg, D., 2003: Evaluating the effectiveness of policies related to drunk driving. J. Policy Anal. Manage., 22, 249-274, https://doi.org/10.1002/pam.10116.

Flanigan, M., K. Majka, A. Blatt, and K. Lee, 2014: Improving the quality of weather information provided to emergency medical services responding to motor vehicle crashes. Transp. Res. Rec., 26-33, https://doi .org/10.3141/2440-04.

Grazioli, J., D. Tuia, and A. Berne, 2015: Hydrometeor classification from polarimetric radar measurements: A clustering approach. Atmos. Meas. Tech., 8, 149-170, https://doi.org/10.5194/amt-8-149-2015.

Hambly, D., J. Andrey, B. Mills, and C. Fletcher, 2013: Projected implications of climate change for road safety in Greater Vancouver, Canada. Climatic Change, 116, 613-629, https://doi.org/10.1007/s10584 -012-0499-0.

Hrachowitz, M., and M. Weiler, 2011: Uncertainty of precipitation estimates caused by sparse gauging networks in a small, mountainous watershed. J. Hydrol. Eng., 16, 460-471, https://doi.org/10.1061 /(ASCE)HE.1943-5584.0000331.

Jaroszweski, D., and T. McNamara, 2014: The influence of rainfall on road accidents in urban areas: A weather radar approach. Travel Behav. Soc., 1, 15-21, https://doi.org/10.1016/j.tbs.2013.10.005.

Jin, P., A. Walker, M. Cebelak, and C. Walton, 2014: Determining strategic locations for environmental sensor stations with weather-related crash data. Transp. Res. Rec., 34-42, https://doi.org/10.3141 12440-05.

Karl, T. R., and W. J. Koss, 1984: Regional and national monthly, seasonal, and annual temperature weighted by area, 1895-1983. Historical Climatology Series 4-3, National Climatic Data Center, 38 pp.

Krajewski, W. F., A. A. Ntelekos, and R. Goska, 2006: A GIS-based methodology for the assessment of weather radar beam blockage in mountainous regions: Two examples from the US NEXRAD network. Comput. Geosci., 32, 283-302, https://doi .org/10.1016/j.cageo.2005.06.024.

Kunkel, K. E., and Coauthors, 2013: Monitoring and understanding trends in extreme storms: State of knowledge. Bull. Amer. Meteor. Soc., 94, 499-514, https://doi.org/10.1175/BAMS-D-11-00262.1.

Maddox, R. A., J. Zhang, J. J. Gourley, and K. W. Howard, 2002: Weather radar coverage over the contiguous United States. Wea. Forecasting, 17, 927-934, https:// doi.org/10.1175/1520-0434(2002)017<0927:WRCOTC $>2.0 . \mathrm{CO} ; 2$.

Mills, B. N., J. Andrey, and D. Hambly, 2011: Analysis of precipitation-related motor vehicle collision and injury risk using insurance and police record 
information for Winnipeg, Canada. J. Safety Res., 42, 383-390, https://doi.org/10.1016/j.jsr.2011.08.004.

National Center for Health Statistics, 2017: 10 leading causes of death by age group highlighting unintentional injury deaths, United States. Centers for Disease Control and Prevention, www.cdc.gov/injury /wisqars/leadingcauses.html.

NHTSA, 2018: Fatality Analysis Reporting System (FARS). National Highway Traffic Safety Administration, accessed 12 February 2018, www.nhtsa. gov/FARS.

Nelson, B. R., J. Zhang, S. Stevens, S. Wilkens, and NOAA CDR Program, 2017: NOAA Climate Data Record (CDR) of NEXRAD Quantitative Precipitation Estimates (QPE), version 1.0. NOAA National Centers for Environmental Information, accessed 24 September 2018, https://doi.org/10.7289/V58C9TG0.

Nelson, E., P. Atchley, and T. D. Little, 2009: The effects of perception of risk and importance of answering and initiating a cellular phone call while driving. Accid. Anal. Prev., 41, 438-444, https://doi .org/10.1016/j.aap.2009.01.006.

Perrels, A., A. Votsis, V. Nurmi, and K. Pilli-Sihvola, 2015: Weather conditions, weather information and car crashes. ISPRS Int. J. Geoinf., 4, 2681-2703, https://doi.org/10.3390/ijgi4042681.

Peterson, T. C., and Coauthors, 2013: Monitoring and understanding changes in heat waves, cold waves, floods, and droughts in the United States: State of knowledge. Bull. Amer. Meteor. Soc., 94, 821-834, https://doi.org/10.1175/BAMS-D-12-00066.1.

Pisano, P., and L. Goodwin, 2004: Research needs for weather-responsive traffic management. Transp. Res. Rec., 1867, 127-131, https://doi.org/10.3141/1867-15.

- - _ safety and operations: the impacts of weather within the context of climate change. The Potential Impacts of Climate Change on Transportation Workshop Summary and Proceedings, U.S. Department of Transportation, 165-184.

Qiu, L., and W. Nixon, 2008: Effects of adverse weather on traffic crashes: Systematic review and metaanalysis. Transp. Res. Rec., 2055, 139-146, https:// doi.org/10.3141/2055-16.

Saha, S., P. Schramm, A. Nolan, and J. Hess, 2016: Adverse weather conditions and fatal motor vehicle crashes in the United States, 1994-2012. Environ. Health, 15, 104, https://doi.org/10.1186/s12940-016-0189-x.
Stenz, R., X. Dong, B. Xi, and R. J. Kuligowski, 2014: Assessment of SCaMPR and NEXRAD Q2 precipitation estimates using Oklahoma Mesonet observations. J. Hydrometeor., 15, 2484-2500, https://doi .org/10.1175/JHM-D-13-0199.1.

Stevens, S. E., 2019: Trends in Instrument Flight Rules (IFR) conditions at major airports in the United States. J. Appl. Meteor. Climatol., 58, 615-620, https:// doi.org/10.1175/JAMC-D-18-0301.1.

Stow, C., and K. Dirks, 1998: High-resolution studies of rainfall on Norfolk Island: Part 1: The spatial variability of rainfall. J. Hydrol., 208, 163-186, https:// doi.org/10.1016/S0022-1694(98)00154-1.

Strayer, D. L., F. A. Drews, and D. J. Crouch, 2006: A comparison of the cell phone driver and the drunk driver. Hum. Factors, 48, 381-391, https://doi .org/10.1518/001872006777724471.

Sun, X., H. Hu, E. Habib, and D. Magri, 2011: Quantifying crash risk under inclement weather with radar rainfall data and matched-pair method. J. Transp. Saf. Secur., 3, 1-14, https://doi.org/10.1080/19439962 .2010 .524348 .

Tamerius, J., X. Zhou, R. Mantilla, and T. GreenfieldHuitt, 2016: Precipitation effects on motor vehicle crashes vary by space, time, and environmental conditions. Wea. Climate Soc., 8, 399-407, https:// doi.org/10.1175/WCAS-D-16-0009.1.

USGCRP, 2018: Impacts, risks, and adaptation in the United States. Vol. II, Fourth National Climate Assessment, D. R. Reidmiller et al., Eds., U.S. Global Change Research Program, 1515 pp., https://doi .org/10.7930/NCA4.2018.

Veneziano, D., Z. Ye, and I. Turnbull, 2014: Speed impacts of an icy curve warning system. IET Intell. Transp. Syst., 8, 93-101, https://doi.org/10.1049/iet -its.2012.0110.

Wu, W., D. Kitzmiller, and S. Wu, 2012: Evaluation of radar precipitation estimates from the National Mosaic and Multisensor Quantitative Precipitation Estimation System and the WSR-88D precipitation processing system over the conterminous United States. J. Hydrometeor., 13, 1080-1093, https://doi .org/10.1175/JHM-D-11-064.1.

Zhang, J., and Coauthors, 2011: National Mosaic and Multi-Sensor QPE (NMQ) system: Description, results, and future plans. Bull. Amer. Meteor. Soc., 92, 1321-1338, https://doi.org/10.1175/2011BAMS -D-11-00047.1. 
New Benefit for AMS Members!

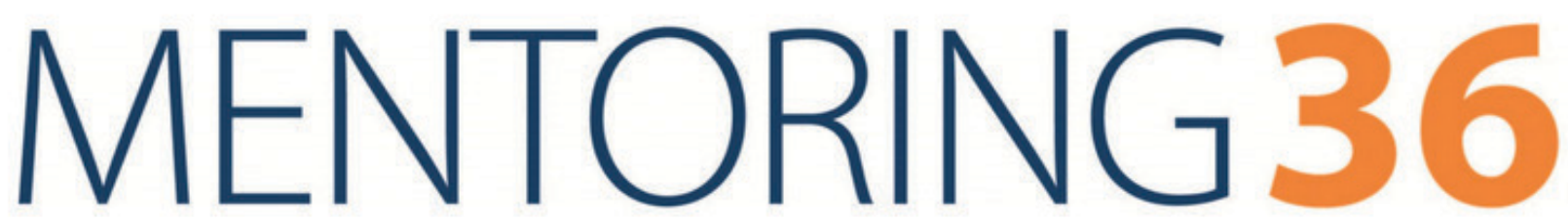

\section{Reach Your Full Potential}

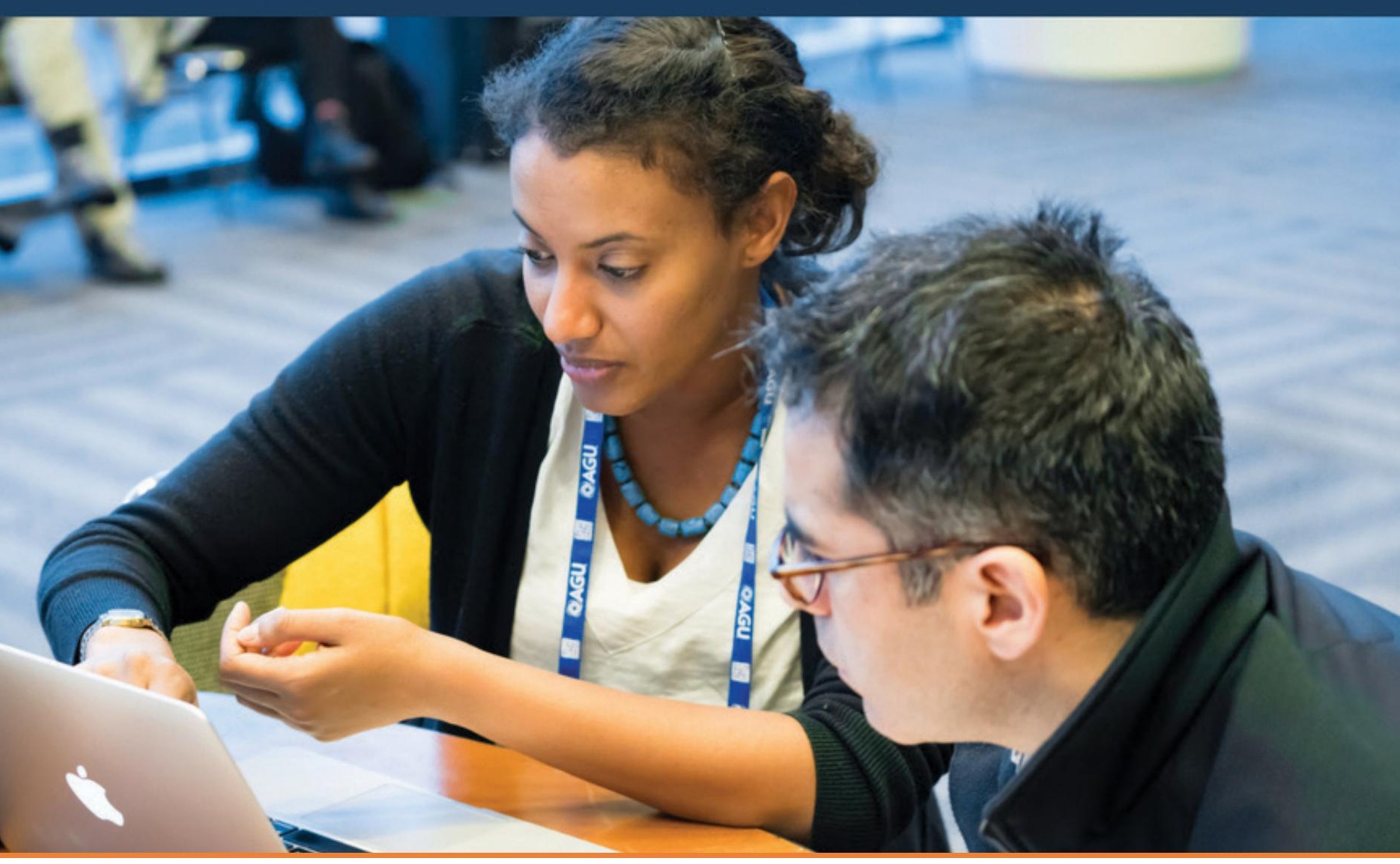

Developed in partnership with Earth and space science organizations, Mentoring365 provides mentors and mentees with structured relationship-building tools to develop and attain focused career goals.

(9) AMS www.mentoring365.org 